\title{
Supportive care needs of individuals with lung cancer
}

by Margaret I. Fitch and Rose Steele

\section{Abstract}

The main purpose of this study was to identify the range of supportive care needs of patients diagnosed with lung cancer who attended an outpatient, regional cancer centre. Lung cancer has more than a physical impact on those who are diagnosed with the disease, yet relatively little has been reported on their needs beyond those for physical symptom management.

A total of 86 patients participated in this study by completing a self-report questionnaire. The data provided clear indication that a range of needs, both physical and psychosocial, exist for this group of patients and, furthermore, remain unmet. Lack of energy, pain, and concern about those close to them were reported most frequently. Patients also expressed distress because of difficulty managing their needs and many indicated wanting help to cope with the challenges they were experiencing. However, a sizeable proportion (45\% to 58\%) indicated they did not want help from staff at the cancer centre for some need items despite considerable distress arising from those remaining unmet (e.g., lack of energy, fears about cancer spreading, not being able to do the things you used to do). Suggestions for practice and future research are offered to improve the care for this group of patients.

\section{Besoins en soins de soutien des personnes atteintes de cancer du poumon}

\section{Abrégé}

Le but principal de la présente étude était de déterminer la gamme des besoins en soins de soutien des patients diagnostiqués d'un cancer du poumon et fréquentant, en ambulatoire, un centre régional de cancérologie. Le cancer du poumon n'a pas seulement un impact physique sur les personnes qu'il frappe, cependant, relativement peu de recherches ont été effectuées sur leurs besoins, mis à part les besoins liés à la gestion des symptômes physiques.

Un total de 86 patients a participé à cette étude en remplissant un questionnaire d'auto-évaluation. Les données indiquaient clairement qu'il existe chez ce groupe de patients une gamme de besoins à la fois physiques et psychosociaux et que ceux-ci demeurent insatisfaits. Ils rapportaient le plus fréquemment un manque d'énergie, des douleurs et des inquiétudes pour leurs proches. Les patients exprimaient également de la détresse parce qu'ils avaient de la difficulté à gérer leurs besoins; beaucoup rapportaient vouloir obtenir de l'aide face aux défis qu'ils rencontraient. Toutefois, une proportion assez importante (de 45 à $58 \%$ d'entre eux) indiquaient ne pas vouloir recevoir d'aide du personnel du centre de cancérologie pour certains de leurs besoins particuliers malgré l'énorme détresse provoquée par l'insatisfaction de leurs besoins (p. ex. le manque d'énergie, la peur que le cancer ne se propage, ne plus être capables de faire les choses qu'ils faisaient auparavant). Des suggestions relatives à la pratique et aux recherches à réaliser à l'avenir sont offertes en vue d'améliorer les soins prodigués à ce groupe de patients.
Although the number of Canadians who are diagnosed with lung cancer is decreasing, lung cancer remains the leading cause of cancer death in Canada for both genders (National Cancer Institute of Canada [NCIC], 2008). About $14 \%$ of the cancer deaths in men $(\mathrm{n}=12,600)$ and women $(\mathrm{n}=11,300)$ are attributable to lung cancer alone. Its relative frequency and poor survival rate make lung cancer the leading cause of premature deaths due to cancer. Despite the advances in cancer therapies, the five-year relative survival is only $13 \%$ for men and $18 \%$ for women (NCIC). Many patients with lung cancer face difficulties in coping with their daily activities, thus making the delivery of supportive care extremely important (Sarna et al., 2004). While information is growing about the supportive care needs of patients with lung cancer, there is a paucity of knowledge about the type of help these patients might require during their experience with cancer.

\section{Literature review}

Most patients with lung cancer experience a rapid and fatal course of illness because of the poor prognosis. The increasing severity of symptoms can make it challenging to manage activities of daily living. Symptoms such as breathlessness (e.g., Edmonds, Karlsen, Khan \& Addington-Hall, 2001; Krishnasamy, Wilkie \& Haviland, 2001; Sarna et al., 2004), coughing (e.g., Bailey, Parmar \& Stephens, 1998; Given, Given \& Stommel, 1994; Hopwood \& Stephens, 1995; Sarna et al., 2004), anorexia (e.g., Sarna, Lindsey, Dean, Brecht \& McCorkle, 1994), and weight loss (e.g., Brown \& Radke, 1998) all have been reported previously. In a recent study designed to better understand the symptom experience of individuals with lung cancer, fatigue and pain were the most frequently identified symptoms. However, the study also emphasized that patients were dealing with several symptoms at one time (Kiteley \& Fitch, 2006).

The diagnosis of cancer and its treatment have more than a physical impact, as social, emotional, psychological, spiritual, and practical consequences also frequently emerge for individuals who are living with cancer (Ashbury, Findley, Reynolds \& McKerracher, 1998; Charles, Sellick, Montesanto \& Mohide, 1996; Whelan et al., 1997). In particular, as disease and symptoms progress and become more pronounced, patients may experience a variety of difficulties in coping with the situation (Bradley, Davis \& Chow, 2005; Bruera et al., 2001; Sarna et al., 2004). Low functioning is significantly associated with a high proportion of patients experiencing unmet needs in personal care, information, communication, occupational functioning, and emotional closeness (Morasso et al., 1999).

The severity of physical symptoms and functional impairment have been linked with quality of life in lung cancer patients. Hopwood and Stephens (2000) reported that depression is common and persistent in patients with lung cancer and functional impairment is the most important risk factor in the development of depression. Each increment in physical impairment increased depression by $41 \%$.

Dr. Margaret I. Fitch, RN, PhD, Head, Oncology Nursing and Supportive Care, Toronto-Sunnybrook Regional Cancer Centre. E-mail: marg.fitch@sunnybrook.ca

Dr. Rose Steele, RN, PhD, Professor, School of Nursing, Rm. 342 HNES Building, Faculty of Health, York University, Toronto, ON M3J 1P3.E-mail: rsteele@yorku.ca 
Trippoli, Varani, Lucioni, and Messori (2001) reported that metastatic disease, with its increase in bodily pain and decrease in physical functioning, had the greatest impact on quality of life. Fluctuations in quality of life also have been reported for lung cancer patients receiving treatment when side effects are also an issue (Hollen, Gralla \& Rittenberg, 2004; John, 2001). Emotional distress, family distress, and impact on sexual functioning are associated with lowered quality of life for females with lung cancer (Sarna et al., 2005). Chapple, Ziebland, and MacPherson (2004) described how stigma associated with lung cancer has a profound effect on those living with the disease. Sarna et al. (2004) reported that primary predictors of lower quality of life were ethnicity and distress mood in 142 five-year survivors of lung cancer. In a mixed method study, Maliski, Sarna, Evangelista, and Padilla (2003) found that $31 \%$ of lung cancer survivors were depressed and were inclined towards a more negative outlook on life than the non-depressed group. These authors suggested that quality of life could be improved if health professionals provided appropriate interventions.

Emotional or psychosocial distress is reported as a common experience for cancer patients, not only during the time directly following diagnosis, but particularly as one's condition deteriorates. Zabora, Brintzenhofeszoc, Curbow, Hooker, and Piantadosi (2001) noted that approximately $20 \%$ of cancer patients experience a significantly elevated level of distress after a new diagnosis. Krishnasamy et al. (2001) reported that about two-thirds of the patients with lung cancer in their study described feelings of anxiety. Conversely, professional caregivers estimated that anxiety would be a problem in less than a quarter of these same patients. Evidence is emerging that patients with unmet needs show significantly higher psychological and symptom distress (Maliski et al., 2003). Further, unresolved psychosocial distress, in particular depression, has been associated with shorter survival (Fallen \& Schmidt, 2004).

Dealing with the consequences of lung cancer and its treatment can be taxing for the person and his or her family (Kiteley \& Fitch, 2006). While some people, given appropriate information and therapeutic relationships with the cancer care team, are able to mobilize their own resources to cope with their cancer experiences, others require additional assistance. Relatively little is known, however, about the full range of assistance people require. Of note, Bruera et al. (2001) demonstrated that patients $(n=166)$ obtained statistically significant psychosocial improvement when they received assistance from members of a multidisciplinary team who could respond to both biologic and psychosocial issues.

While some information is known about the supportive care needs of patients with lung cancer, there is a paucity of knowledge about the full range of needs and, in particular, what type of help patients actually want to meet their needs. Such information is important for several reasons: 1) to plan a patient's individual care, 2) to make decisions about resource allocation, and 3) to identify potential areas for improving the quality of care delivery.

\section{Purpose}

The primary purpose of this cross-sectional, descriptive study was to identify the range of needs (physical, emotional, social, spiritual, psychological, and practical) of patients with lung cancer who attended a comprehensive, ambulatory cancer centre. A second purpose was to determine if patients wanted assistance in meeting those needs.

\section{Method}

\section{Sample accrual and data collection}

The study commenced once ethical approval had been received from the university and hospital ethics committees. A research associate (RA) consulted with staff in the lung clinic to identify potential participants. Patients were eligible if they had a definitive diagnosis of cancer and were more than 18 years of age. Patients were approached in the reception area of the lung clinic by the RA who explained the study objectives and participation and invited the person to participate. Those who agreed to participate signed a consent form in duplicate. The patient kept one copy and the RA retained the other.

The RA gave each participating patient a questionnaire and assessed if the patient required assistance to complete it. If assistance was required (e.g., because of physical disability), the RA took the patient to a quiet, private room and completed the questionnaire through a structured interview format. For those patients who agreed to complete the questionnaire by themselves during their clinic visit, the RA checked back with the patient at a specified time to collect the completed questionnaire. There also was a box in the clinic for patients to leave completed questionnaires in a sealed envelope. Finally, if a patient was unable to complete the questionnaire during his/her clinic visit, the RA provided a stamped, addressed envelope in which to return the questionnaire.

To minimize exclusion of patients who did not speak, read, and/or write English, accompanying family or friends who were fluent in the English language were invited to explain the study to those patients and were asked to provide translation if they and the patient both agreed. All answers were completed on the form in English. The patient signed the consent form and the translator also signed and made a notation that the patient's consent was voluntary. The RA kept track of how the questionnaires were completed (by the patient directly, through an interview format with the RA, or through an interpreter). There were no differences noted between these groups in the analysis.

\section{Measurement tool}

Data were collected using a self-report questionnaire. Part I was a demographic form including eight questions: age in years, gender, marital status, highest level of education completed, type of cancer, month and year when cancer first diagnosed, treatment received for the cancer, and treatment currently being given for the cancer. Patients checked all that applied for both treatment questions.

Part II of the questionnaire was an adaptation of the Supportive Care Needs Survey originally developed and validated in Australia (Bonevski et al., 2000). The original tool contained 60 closed-ended items to which patients respond on a five-point Likert scale. As defined, the scale reflects various levels of need ranging from "no need" (i.e., item is not an issue for the patient as a result of having cancer) to a high need for help (i.e., the item is of major concern or importance to the patient and the patient has a strong need for additional help with the problem or issue). The specific wording for each item response is as follows: I did not experience this issue; I experienced this issue, but it has been looked after; I am experiencing a low level of difficulty with this issue; I am experiencing a moderate level of difficulty with this issue; and I am experiencing a high level of difficulty with this issue. The measurement tool is readily comprehended by individuals with minimal education and can be completed in 20 minutes.

The original principal components factor analysis (Bonevski et al., 2000) revealed items grouped under five factors (domains): 1) psychological -items related to emotions and coping; 2) health system and information - items related to the treatment centre and information about the disease, treatment, and follow-up; 3) physical and daily living - items related to coping with physical symptoms, side effects of treatment, and performing usual physical tasks and activities; 4) patient care and support-items related to health care providers showing sensitivity to physical and emotional needs, privacy, and choice; and 5) sexuality - items related to sexual relationships. Cronbach's alpha coefficients for the five factors ranged from 0.87 for sexuality to 0.97 for psychological. Four other items were not associated with a 
specific factor loading-transportation, other people's attitudes toward the patient, finances, and talking with other individuals.

Prior to use in the study reported in this article, the original instrument was adapted by the research team. A review of the original Bonevski tool with lung cancer patients at our cancer centre identified the value of reordering some questions for improved clarity and rewording them to reflect the ambulatory setting. The team also added a new question about desire for help to each need item. Thus, patients were asked to indicate if they wished to have help in dealing with the need (i.e., No, I do not want any help; Yes, I would like help; I feel uncertain about wanting help). The Adapted Supportive Care Needs Survey covers the seven domains of supportive care (Fitch, Porter \& Page, 2008) over 61 items: emotional (11 items), informational (nine items), physical (symptoms; 11 items), practical (seven items), psychological (11 items), social (five items), and spiritual (seven items). Our psychometric analysis of the revised tool revealed encouraging results for lung cancer patients. Cronbach's alphas for the subscales (the domains) ranged from 0.66 to 0.90 , with six of the seven subscales having an alpha of 0.80 or higher.

Table One. Demographic variables:

Patients with lung cancer $(n=86)$

\begin{tabular}{|l|l|l|}
\hline \multicolumn{2}{|l|}{ Characteristics } & $\mathrm{n}=86$ \\
\hline Gender & Male & 34 \\
& Female & 49 \\
& Missing data & $(3)$ \\
\hline Age in Years & $<45$ & 6 \\
& $45-65$ & 37 \\
& $>65$ & 43 \\
\hline Marital Status & Married & 67 \\
& Widowed/Divorced & 14 \\
& Never Married & 2 \\
& Missing data & $(3)$ \\
\hline Education & $<$ College & 53 \\
& $\geq$ College & 29 \\
& Missing data & $(4)$ \\
\hline Time Since Diagnosis & $<1$ year & 24 \\
& $1-2$ years & 31 \\
& $>2$ years & 31 \\
\hline
\end{tabular}

\section{Analysis}

Analysis was descriptive and focused on item frequency and the seven supportive care domain subscale scores. Patients were classified as currently experiencing an issue if they endorsed either 3 , 4 , or 5 in the response options for an item. They were classified as distressed based on their endorsement of the level of difficulty they were experiencing with the issue (i.e., $3=$ low distress, $4=$ moderate distress, $5=$ high distress $)$. Tests of difference were used to determine the influence of selected demographic variables on the level of expressed need (t-tests for the dichotomous, categorical variables gender and education level; ANOVA for the multi-level, categorical variables marital status, time since diagnosis, and age). Significance level was set at $\mathrm{p}<.05$ for these tests.

\section{Help desired}

Patients who were currently experiencing an issue also were asked to indicate if they wished to have help in dealing with the need. The assumption was made that anyone who was "uncertain" warranted a conversation with staff, at a minimum. Therefore, responses from those who reported "uncertain" about wanting help were added to those who reported "yes" to wanting help. The total was divided by the number of respondents who had reported they were currently experiencing the issue. These calculations determined the percentages of patients with a current issue who wanted some type of help.

\section{Results Sample}

A convenience sample of 86 patients participated in the study. Approximately three-fifth's of the sample were women (59\%). Similar to the clinic population, the sample was older with half being more than 65 years of age. Most patients were married (77\%), slightly more than one-third had at least a college level education, and $41 \%$ had been diagnosed between one and two years (see Table One).

No tests of difference were statistically significant except for gender on the scores for the Practical subscale. On this subscale women had slightly higher mean scores than men $(\mathrm{t}=2.0157$, $p=.0478)$. Therefore, results are reported for the entire sample.

\section{Issues currently experienced}

Patients reported currently experiencing issues across all seven need domains and for virtually all items. The number of patients experiencing an issue ranged from as few as four participants for the item "family and friends to be allowed with you in hospital

Table Two. Physical needs $(n=86)$

\begin{tabular}{|c|c|c|c|c|}
\hline Issue & $\begin{array}{l}\text { Currently } \\
\text { experiencing issue }\end{array}$ & Want help & $\begin{array}{l}\text { Uncertain if } \\
\text { want help }\end{array}$ & $\begin{array}{l}\text { Want help or } \\
\text { are uncertain/\% }\end{array}$ \\
\hline Lack of energy & 59 & 21 & 11 & $32 / 54.2 \%$ \\
\hline Not being able to do things you used to do & 52 & 13 & 10 & $23 / 44.2 \%$ \\
\hline Shortness of breath & 42 & 11 & 7 & $18 / 42.9 \%$ \\
\hline Coughing & 40 & 9 & 8 & $17 / 42.5 \%$ \\
\hline Not being able to work around at home & 39 & 10 & 6 & $16 / 41.0 \%$ \\
\hline Feeling unwell & 35 & 10 & 7 & $17 / 48.6 \%$ \\
\hline Pain & 29 & 13 & 6 & $19 / 65.5 \%$ \\
\hline Decreased appetite & 26 & 8 & 3 & $11 / 42.3 \%$ \\
\hline Changes in sexual feelings & 23 & 1 & 8 & $9 / 39.1 \%$ \\
\hline Nausea/vomiting & 13 & 8 & 2 & $10 / 76.9 \%$ \\
\hline Hospital staff to attend promptly to your physical needs & 9 & 5 & 3 & $8 / 88.9 \%$ \\
\hline
\end{tabular}


whenever you want" (social domain) to as many as 59 participants endorsing the "lack of energy" item (physical domain). All domains had at least one item where $25 \%$ or more of the patients reported experiencing it as an issue at the time they completed the questionnaire. For the purposes of this report, items where $25 \%$ or more of the patients reported currently experiencing an issue will be highlighted in the text. All items are presented in Tables Two to Eight.

Physical needs. Out of the 11 physical items, nine items were reported as current issues for at least $25 \%$ of patients: lack of energy $(n=59)$; not being able to do things you used to do $(n=52)$; shortness of breath $(n=42)$; coughing $(n=40)$; not being able to work around the home $(n=39)$; feeling unwell $(n=35)$; pain $(n=29)$; decreased appetite $(n=26)$; and changes in sexual feelings $(n=23)$ (see Table Two).

Emotional needs. At least a quarter of the patients reported currently experiencing issues in six of the 11 emotional items: feeling down or depressed $(n=40)$; feelings of sadness $(n=35)$; feeling bored and/or useless $(n=34)$; anxiety $(n=33)$; worry that the results of your treatment are beyond your control $(\mathrm{n}=29)$; and anxiety about having treatment $(\mathrm{n}=26)$ (see Table Three).

Psychological needs. For six of the 11 psychosocial items at least $25 \%$ of patients reported a current issue: fears about cancer spreading $(\mathrm{n}=58)$; fears about cancer returning $(\mathrm{n}=49)$; fears about pain $(\mathrm{n}=$ $44)$; fears about physical disability or deterioration $(n=34)$ learning to feel in control of your situation $(n=29)$; and fears about losing your independence $(\mathrm{n}=27)$ (see Table Four).

Spiritual needs. Three of the seven spiritual items were reported as an issue for more than $25 \%$ of the patients. Forty-two patients reported currently experiencing uncertainty about the future. Feelings about death and dying were experienced by 32 patients and the other item currently experienced by at least $25 \%$ of the patients was keeping a positive outlook $(\mathrm{n}=22)$ (see Table Five).

Social needs. Having concerns about the worries of those close to you $(n=38)$ and concerns about the ability of those close to you to cope with caring for you $(n=25)$ were the two (out of five) social items for which at least a quarter of the patients reported as current issues for them (see Table Six).

\begin{tabular}{|l|l|l|l|l|}
\hline Table Three. Emotional needs (n = 86) \\
\hline Issue & $\begin{array}{l}\text { Currently } \\
\text { experiencing issue }\end{array}$ & Want help & $\begin{array}{l}\text { Uncertain if } \\
\text { want help }\end{array}$ & $\begin{array}{l}\text { Want help or } \\
\text { are uncertain/\% }\end{array}$ \\
\hline Feeling down or depressed & 40 & 11 & 10 & $21 / 52.5 \%$ \\
\hline Feelings of sadness & 35 & 6 & 10 & $16 / 45.7 \%$ \\
\hline Feeling bored and/or useless & 34 & 10 & 7 & $17 / 50.0 \%$ \\
\hline Anxiety & 33 & 11 & 10 & $21 / 63.6 \%$ \\
\hline Worry that the results of your treatment are beyond your control & 29 & 9 & 7 & $16 / 55.2 \%$ \\
\hline Anxiety about having any treatment & 26 & 12 & 1 & $13 / 50.0 \%$ \\
\hline To have one member of hospital staff with whom you talk & 18 & 10 & 4 & $14 / 77.8 \%$ \\
\hline Changes in sexual relationships & 16 & 1 & 3 & $4 / 25.0 \%$ \\
\hline To be treated like a person, not just another case & 16 & 8 & 4 & $12 / 75.0 \%$ \\
\hline $\begin{array}{l}\text { The opportunity to talk with someone who understands } \\
\text { and has been through similar experience }\end{array}$ & 12 & 7 & 1 & $8 / 66.7 \%$ \\
\hline Hospital staff to acknowledge and show sensitivity to your feelings & 7 & 5 & 1 & $6 / 85.7 \%$ \\
\hline
\end{tabular}

Table Four. Psychological needs $(n=86)$

\begin{tabular}{|l|l|l|l|l|}
\hline Issue & $\begin{array}{l}\text { Currently } \\
\text { experiencing issue }\end{array}$ & Want help & $\begin{array}{l}\text { Uncertain if } \\
\text { want help }\end{array}$ & $\begin{array}{l}\text { Want help or } \\
\text { are uncertain/\% }\end{array}$ \\
\hline Fears about cancer spreading & 58 & 21 & 11 & $32 / 55.2 \%$ \\
\hline Fears about cancer returning & 49 & 18 & 10 & $28 / 57.1 \%$ \\
\hline Fears about pain & 41 & 18 & 5 & $23 / 56.1 \%$ \\
\hline Fears about physical disability or deterioration & 34 & 17 & 5 & $21 / 61.8 \%$ \\
\hline Learning to feel in control of your situation & 29 & 12 & 7 & $19 / 65.5 \%$ \\
\hline Fears about losing your independence & 27 & 11 & 6 & $17 / 63.0 \%$ \\
\hline Accepting changes in your physical appearance & 21 & 7 & 4 & $11 / 52.4 \%$ \\
\hline Reassurance by the medical staff that the way you feel is normal & 15 & 9 & 4 & $13 / 86.7 \%$ \\
\hline To have access to professional counselling if you or family need it & 12 & 6 & 4 & $10 / 83.3 \%$ \\
\hline To be treated in a hospital or clinic that is pleasant & 10 & 4 & 4 & $8 / 80.0 \%$ \\
\hline More fully protected rights to privacy when you are at the hospital & 7 & 3 & 2 & $5 / 71.4 \%$ \\
\hline
\end{tabular}


Informational needs. Only two out of nine items in the informational domain were experienced as issues by more than $25 \%$ of the lung cancer patients: to be given information about aspects of managing your illness and side effects of treatment $(n=24)$ and to be informed about test results as soon as possible $(n=22)$ (see Table Seven).

Practical needs. Three of the seven items in this domain were reported as a currently experienced issue by at least $25 \%$ of patients: changes in usual routine and lifestyle $(n=31)$, waiting for a long time for clinics appointments $(n=27)$, and concerns about your financial situation $(\mathrm{n}=22)$ (see Table Eight).

\section{Most frequently reported items} and self-identified distress

More than $45 \%$ of the patients reported currently experiencing the most frequently endorsed items. Of the nine most frequently reported issues, four were from the physical domain (lack of energy, not being able to do things you used to do, shortness of breath, and coughing); three were psychological (fears about cancer spreading, fears about cancer returning, and fears about pain); one was spiritual (uncertainty about the future); and one was emotional (feeling down or depressed) (see Table Nine).

Table Five. Spiritual needs $(\mathbf{n}=\mathbf{8 6})$

\begin{tabular}{|c|c|c|c|c|}
\hline Issue & $\begin{array}{l}\text { Currently } \\
\text { experiencing issue }\end{array}$ & Want help & $\begin{array}{l}\text { Uncertain if } \\
\text { Want help }\end{array}$ & $\begin{array}{l}\text { Want help or } \\
\text { are uncertain/\% }\end{array}$ \\
\hline Uncertainty about the future & 42 & 14 & 11 & $25 / 59.5 \%$ \\
\hline Feelings about death and dying & 32 & 8 & 10 & $18 / 56.3 \%$ \\
\hline Keeping a positive outlook & 22 & 6 & 8 & $14 / 63.6 \%$ \\
\hline Confusion about why this has happened to you & 19 & 6 & 5 & $11 / 58.9 \%$ \\
\hline Making the most of your time & 19 & 9 & 4 & $13 / 68.4 \%$ \\
\hline Finding meaning in this experience & 17 & 5 & 5 & $10 / 58.8 \%$ \\
\hline Hospital staff to convey a sense of hope & 14 & 2 & 5 & $7 / 50.0 \%$ \\
\hline
\end{tabular}

Table Six. Social needs $(n=86)$

\begin{tabular}{|l|l|l|l|}
\hline Issue & $\begin{array}{l}\text { Currently } \\
\text { experiencing issue }\end{array}$ & $\begin{array}{l}\text { Want help } \\
\text { Uncertain if } \\
\text { want help }\end{array}$ & $\begin{array}{l}\text { Want help or } \\
\text { are uncertain/\% }\end{array}$ \\
\hline Concerns about the worries of those close to you & 38 & 9 & 10 \\
\hline $\begin{array}{l}\text { Concerns about the ability of those close to you to cope } \\
\text { with caring for you }\end{array}$ & 25 & 10 & 4 \\
\hline Changes in people's attitudes and behaviours towards you & 12 & 5 & $4 / 50.0 \%$ \\
\hline $\begin{array}{l}\text { Talking to other people about the cancer } \\
\text { Family and friends to be allowed with you in hospital } \\
\text { whenever you want }\end{array}$ & 4 & 5 & 2 \\
\hline
\end{tabular}

Table Seven. Informational needs $(n=86)$

\begin{tabular}{|c|c|c|c|c|}
\hline Issue & $\begin{array}{l}\text { Currently } \\
\text { experiencing issue }\end{array}$ & Want help & $\begin{array}{l}\text { Uncertain if } \\
\text { want help }\end{array}$ & $\begin{array}{l}\text { Want help or } \\
\text { are uncertain/\% }\end{array}$ \\
\hline $\begin{array}{l}\text { To be given information about aspects of managing your illness } \\
\text { and side effects of treatment }\end{array}$ & 24 & 13 & 5 & $18 / 75.0 \%$ \\
\hline To be informed about test results as soon as possible & 22 & 11 & 6 & $17 / 77.3 \%$ \\
\hline To be informed about the things you can do to help yourself get well & 20 & 15 & 3 & $18 / 90.0 \%$ \\
\hline $\begin{array}{l}\text { To be informed about cancer that is under control } \\
\text { or diminishing (in remission) }\end{array}$ & 20 & 10 & 5 & $15 / 75.0 \%$ \\
\hline $\begin{array}{l}\text { To be adequately informed about the benefits and } \\
\text { side effects of treatment }\end{array}$ & 19 & 12 & 5 & $17 / 89.5 \%$ \\
\hline To be given written information about important aspects of your care & 18 & 12 & 3 & $15 / 83.3 \%$ \\
\hline $\begin{array}{l}\text { To be given explanations of those tests for which } \\
\text { you would like explanations }\end{array}$ & 17 & 10 & 3 & $13 / 76.5 \%$ \\
\hline To be informed about support groups in your area & 12 & 6 & 4 & $10 / 83.3 \%$ \\
\hline To be given information about sexual relationships & 10 & 3 & 4 & $7 / 70.0 \%$ \\
\hline
\end{tabular}


The patients who were experiencing an issue also were asked to indicate how much distress they were feeling because of a particular issue in terms of low, moderate, or high intensity. The self-identified distress ratings reported for each of the nine most frequently reported items are presented in Table Nine. In four of the nine items, feelings of high distress were reported by at least a quarter of those experiencing the issue. Results concerning those who reported wanting help with a current issue or were "uncertain" about wanting help are presented in Tables Two to Eight.

A high number of people currently experiencing an issue did not necessarily translate into a high percentage who wanted help. For example, 59 patients reported currently experiencing lack of energy, but only 21 indicated definitely wanting help with this issue. In contrast, for some items, even though relatively few people reported experiencing an issue, a high proportion of patients wanted help with it. As an example, informational needs were not in the top nine frequently reported issues. However, $70 \%$ to $90 \%$ of those with issues in this domain wanted help. For all nine information domain items, at least $70 \%$ of patients with an issue wanted help. Other domains were equally dramatic. For many items where $\geq 50 \%$ of patients were experiencing an issue, the proportion who wanted help with it exceeded $50 \%$ (52.4\% to $86.7 \%$, for $11 / 11$ psychosocial items; $50 \%$ to $68.4 \%$, for $7 / 7$ spiritual items; $50 \%$ to $100 \%$, for $5 / 5$ social items). The remaining domains were not as dramatic, although several items revealed more than $50 \%$ of those with an issue wanted help: 4/11 physical items; 8/11 emotional items; and 6/7 practical items. With regards to the nine most frequently reported issues, patients experiencing concerns did not necessarily want help with these top items either. There were only six of nine items where at least $50 \%$ of those patients experiencing an issue wanted help: lack of energy, fears about cancer spreading, fears about cancer returning, uncertainty about the future, feeling down or depressed, and fears about pain (see Table Nine).

\section{Discussion}

This study was undertaken to describe the full range of supportive care needs of patients with lung cancer. Given the methodology of the study, the data provide an indication of the burden of need in this patient population. Clearly, the patients were experiencing more than physical issues and were experiencing a range of issues simultaneously. Further, a sizeable proportion was experiencing high distress because of the issues they were trying to manage. However, additional work is needed to delve more deeply into the situation and illuminate what solutions are best to improve care.

Many of the physical issues identified in this study were similar to those already reported in the literature (Hill, Amir, Muers, Connolly \& Round, 2003; Krishnasamy et al., 2001; Lia \& Girgis, 2006; Montazeri, Milroy, Hole, McEwen \& Gillis, 2003). Further investigation is, perhaps, warranted to determine if patients actually communicated with the staff about their concerns and if the cancer care team is assessing and intervening with these issues. For example, lack of energy is known to be a major issue for a large number of individuals with cancer (Bradley et al., 2005). Overwhelming fatigue affects a person's ability to carry out normal, everyday activities, and the effect of the associated losses can be devastating to a person's well-being (Kennett \& Payne, 2005). Yet, evidence is available regarding how to manage fatigue (Mitchell, Beck, Hood, Moore \& Tanner, 2007). Are staff members aware of

Table Eight. Practical needs $(n=86)$

\begin{tabular}{|c|c|c|c|c|}
\hline Issue & $\begin{array}{l}\text { Currently } \\
\text { experiencing issue }\end{array}$ & Want help & $\begin{array}{l}\text { Uncertain if } \\
\text { want help }\end{array}$ & $\begin{array}{l}\text { Want help or } \\
\text { are uncertain/\% }\end{array}$ \\
\hline Changes in usual routine \& lifestyle & 31 & 9 & 6 & $15 / 48.4 \%$ \\
\hline Waiting a long time for clinic appointments & 27 & 11 & 7 & $18 / 66.7 \%$ \\
\hline Concerns about your financial situations & 22 & 11 & 3 & $14 / 63.6 \%$ \\
\hline Concerns about getting to and from the hospital & 16 & 6 & 5 & $11 / 68.8 \%$ \\
\hline To be given choices about when you go for tests and treatments & 12 & 4 & 5 & $9 / 75.0 \%$ \\
\hline More choice about which hospital you attend & 9 & 4 & 4 & $8 / 88.9 \%$ \\
\hline More choice about the cancer specialist you see & 9 & 4 & 4 & $8 / 88.9 \%$ \\
\hline
\end{tabular}

Table Nine. Patient reported distress linked to current issue

\begin{tabular}{|c|c|c|c|c|c|}
\hline \multirow[t]{2}{*}{ Most frequently identified items } & \multirow{2}{*}{$\begin{array}{l}\text { Reported item as a } \\
\text { current issue }(n=86)\end{array}$} & \multirow[t]{2}{*}{ Desire for help } & \multicolumn{3}{|c|}{ Sense of distress caused by issue } \\
\hline & & & Low & Moderate & High \\
\hline Lack of energy & $59(69 \%)$ & $32(54.2 \%)$ & 25 & 17 & 17 \\
\hline Fears about cancer spreading & $58(67 \%)$ & $32(55.1 \%)$ & 25 & 18 & 15 \\
\hline Not being able to do the things you used to & $52(60 \%)$ & $23(45.3 \%)$ & 21 & 20 & 11 \\
\hline Fears about cancer returning & $49(57 \%)$ & $28(57.1 \%)$ & 20 & 13 & 16 \\
\hline Uncertainty about the future & $42(49 \%)$ & $25(59.5 \%)$ & 18 & 11 & 13 \\
\hline Shortness of breath & $42(49 \%)$ & $18(42.9 \%)$ & 24 & 14 & 4 \\
\hline Fears about pain & $41(48 \%)$ & $23(56.1 \%)$ & 18 & 14 & 9 \\
\hline Coughing & $40(47 \%)$ & $17(42.5 \%)$ & 23 & 14 & 3 \\
\hline Feeling down or depressed & $40(47 \%)$ & $21(52.5 \%)$ & 20 & 14 & 6 \\
\hline
\end{tabular}


the patient issue? Are staff members knowledgeable about suggestions they could provide for managing fatigue and enhancing quality of life or is education needed? Are there other barriers thwarting their intervention efforts? Why are we still seeing high rates of physical symptoms that patients report as concerns or problems? Similar comments can be made about issues of breathlessness for lung cancer patients: shortness of breath also has been reported in the literature and successful interventions tested (Corner, Plant, A'Hern \& Bailey, 1996). Of the physical symptoms, coughing, perhaps, as yet, has received the least attention in terms of interventional research.

Non-physical issues, such as psychological, social, and emotional issues, were among the most frequently reported issues that patients experienced at the time of the survey. In some instances, these issues have been reported previously (Bradley et al., 2005; Bruera et al., 2001; Kennett \& Payne, 2005; Solano \& Higginson, 2006). However, the additional information reported in this study is the significant proportion of individuals who were distressed by the issues they were experiencing. Further work also is warranted here to determine if these issues had been identified by the cancer care team or not. These issues can be overlooked by primary cancer team members when tumour-focused care is seen as a priority (Bultz \& Carlson, 2005; Jacobsen, 2007; Zabora et al., 2001). On the other hand, these psychosocial issues are complex and may require a different setting for in-depth assessment and appropriate intervention. During a typically short ambulatory clinic appointment, it may not be realistic or appropriate to conduct this type of assessment prior to the patient meeting with the clinic staff, nor may the clinic staff have all the requisite knowledge or skill for the depth of interaction this type of assessment would require. However, the dialogue could be opened, the issue flagged, and arrangements made for a future interaction or referral.

There is growing evidence that psychosocial intervention may improve well-being and survival for patients with cancer (Chow, Tsao \& Harth, 2004; Kennett \& Payne, 2005), so it is imperative that attention is paid to this area. Voogt and colleagues (2005) suggested that mood disorders in patients with advanced cancer $(n=105)$ may be related to the absence of positive feelings rather than to a high level of negative feelings. A lack of positive emotions was linked to an inability to engage in meaningful activities and a reduction in cognitive and social functioning, as well as to more fatigue. If professionals can uncover what activities are meaningful to patients and help them continue these activities for as long as possible, or suggest substitute activities when needed, then patients may suffer less psychological distress.

The instrument used in the current study provided comprehensive assessment of needs across the full spectrum of supportive care. Uncovering issues affords professionals the opportunity to provide assistance. However, professionals should not make assumptions that a patient with a concern will always mention the issue to the care provider voluntarily. It is important to ask patients if they are experiencing an issue and if they want help with it. A significant number of people want help with issues, but in those cases where some do not want help, patients' wishes should be honoured. An open discussion with patients can lead to a shared understanding between patient and provider about what would be most helpful from the patient's perspective at a specific point in time. This approach could result in an intervention or not. It also could provide an opportunity for health care professionals to ensure patients know about available resources should they wish to access them in the future. Health care providers need to acknowledge with patients the reality of psychological issues, such as fears about physical disability or deterioration, as well as physical issues. Providers also need to ensure open dialogue and communication with patients so they can direct people to appropriate resources for help.
The proportion of patients who indicated they would like help in resolving specific issues suggests that a number of patients were looking for assistance over and above that which was currently being provided to them. Clearly, even in good cancer centres, patients still have unmet needs (Hill et al., 2003). This observation has implications for future program planning, resource allocation, and research, for both ambulatory clinics and other centres where lung cancer patients receive care. Attention also must be paid to patients who identify needs, but do not want assistance to ensure that staff members support them in the way they desire. At the same time, patients should be assessed on an ongoing basis in case their needs and desires change.

Cancer centres do not have the resources to provide all services to all people. However, they do have a responsibility to patients to ensure that cancer care is optimal across the spectrum of care. The plan of care needs to be comprehensive and consider all areas of need. Collaboration may be required to have different services or agencies provide service(s). Staff at the cancer centre could identify certain problems patients are experiencing, but then ensure those who provide the primary care in the community are aware of the problems. Care can be shared with community providers or agencies and does not need to be directly provided solely within the hospital or clinic environment. Staff could give the patient a letter about his/her treatment, include information about what supportive care issues need to be addressed, and provide the patient with a list of communitybased agencies and contact information.

The notion of having a routine method of efficiently and effectively assessing the full range of needs for patients with lung cancer is emerging as a standard of practice (accreditation). For example, the most frequently identified issues from this study could be used as items for a screening or triage tool that would rapidly identify the individuals with concerns. The identification could provide impetus for a dialogue between the health professional and individual about whether or not that person wants help with the issue. An exploration of patient expectations regarding assistance would enable staff and patients to discuss what steps would be necessary to ensure that patients receive the kind of help they want.

It also is imperative that appropriate resources and interventions are available. In some areas, centres might be able to employ staff, such as an advanced practice nurse, to provide some of the care required. The results from this current study illustrate that issues are present and ought to be handled. The data provide a basis or support for research funding related to supportive care that would identify interventions and develop evidence-based protocols. For example, an in-depth literature review could be conducted to first explore the top three issues identified in this study. Local interventions could then be developed for these issues and tested through a randomized clinical trial (RCT) to compare standard care against the intervention. Finally, patients could be followed in a longitudinal study to assist in identifying which interventions worked and why.

\section{Conclusion}

Patients with lung cancer may have a number of unmet needs for which they require assistance. It is important to identify any issues as efficiently and effectively as possible so that patients can be provided with appropriate resources for help. Physical issues such as lack of energy and pain are experienced by the majority of these patients, but emotional, psychological, social, spiritual, practical, and informational issues also are present for some patients. Interventions must be developed to assist patients in coping with a range of needs during the cancer journey.

\section{Acknowledgement}

Funding for this study was provided by the Ontario Lung Association through an Ontario Respiratory Care Society Research Grant. 
Ashbury, F.D., Findley, H., Reynolds, B., \& McKerracher, K. (1998). A Canadian survey of cancer patients' experiences: Are their needs being met? Journal of Pain and Symptom Management, 16(5), 298-306.

Bailey, A.J., Parmar, M.K.B., \& Stephens, R.J. (1998). Patientreported short-term and long-term physical and psychological symptoms. Journal of Clinical Oncology, 16, 3082-3093.

Bonevski, B., Sanson-Fisher, R., Girgis, A., Burton, L., Cook, P., Boyes, A., et al. (2000). Evaluation of an instrument to assess the needs of patients with cancer. Cancer, 88(1), 217-225.

Bradley, N., Davis, L., \& Chow, E. (2005). Symptom distress in patients attending an outpatient palliative radiotherapy clinic. Journal of Pain and Symptom Management, 30(2), 123-131.

Brown, J., \& Radke, K. (1998). Nutritional assessment, intervention, and evaluation of weight loss in patients with non-small cell lung cancer. Oncology Nursing Forum, 25, 547-553.

Bruera, E., Michaud, M., Vigano, A., Neumann, C., Watanabee, S., \& Hanson, J. (2001). Multidisciplinary symptom control clinic in a cancer centre: A retrospective study. Supportive Care in Cancer, 9, 162-168.

Bultz, B., \& Carlson, L.E. (2005). Emotional distress: The sixth vital sign in cancer care. Journal of Clinical Oncology, 23, 6440-6441.

Chapple, A., Ziebland, S., \& MacPherson, A. (2004). Stigma, shame, and blame experienced by patients with lung cancer: A qualitative study. British Medical Journal, 328, 1470-1474.

Charles, K., Sellick, S.M., Montesanto, B., \& Mohide, E.A. (1996). Priorities for cancer survivors regarding psychosocial needs. Journal of Psychosocial Oncology, 14(2), 57-72.

Chow, E., Tsao, M., \& Harth, T. (2004). Does psychosocial intervention improve survival in cancer? A meta-analysis. Palliative Medicine, 18(1), 25-31.

Corner, J., Plant, H., A'Hern, R., \& Bailey, C. (1996). Nonpharmacological intervention for breathlessness in lung cancer. Palliative Medicine, 10(4), 299-305.

Edmonds, P., Karlsen, S., Khan, S., \& Addington-Hall, J. (2001). A comparison of the palliative care needs of patients dying from chronic respiratory diseases and lung cancer. Palliative Medicine, 15(4), 287-295.

Fallen, H., \& Schmidt, M. (2004). Prognostic value of depressive coping and depression in survival of lung cancer patients. PsychoOncology, 13(5), 359-363.

Fitch, M.I., Porter, H.B., \& Page, B.D. (Eds.). (2008). Supportive care framework: A foundation for person-centred care. Pembroke, ON: Pappin Communications.

Given, C.W., Given, B.A., \& Stommel, M. (1994). The impact of age, treatment, and symptoms on the physical and mental health of cancer patients. Cancer, 74, 2128-2138.

Hill, K.M., Amir, Z., Muers, M.F., Connolly, C.K., \& Round, C.E. (2003). Do newly diagnosed lung cancer patients feel their concerns are being met? European Journal of Cancer Care, 12(1), 35-45.

Hollen, P.J., Gralla, R.J., \& Rittenberg, C.N. (2004). Quality of life as a clinical trial endpoint: Determining the appropriate interval for repeated assessments in patients with advanced lung cancer. Supportive Care in Cancer, 12, 767-773.

Hopwood, P., \& Stephens, R.J. (1995). Symptoms at presentation for treatment in patients with lung cancer: Implications for the evaluation of palliative treatment. British Journal of Cancer, 71, 633-36.

Hopwood, P., \& Stephens, R.J. (2000). Depression in patients with lung cancer: Prevalence and risk factors derived from quality-oflife data. Journal of Clinical Oncology, 18(4), 893-903.
Jacobsen, P.B. (2007). Screening for psychological distress in cancer patients: Challenges and opportunities. Journal of Clinical Oncology, 25, 4526-4527.

John, L.D. (2001). Quality of life in patients receiving radiation therapy for non-small cell lung cancer. Oncology Nursing Forum, 28, 807-813.

Kennett, C., \& Payne, M. (2005). Understanding why palliative care patients "like day care"and "getting out." Journal of Palliative Care, 21(4), 292-298.

Kiteley C., \& Fitch M.I. (2006). Understanding the symptoms experienced by individuals with lung cancer. Canadian Oncology Nursing Journal, 16(1), 25-30.

Krishnasamy, M., Wilkie, E., \& Haviland, J. (2001). Lung cancer health care needs assessment: Patients' and informal carers' responses to a national mail questionnaire survey. Palliative Medicine, 15(3), 213-227.

Lia, J., \& Girgis, A. (2006). Supportive care needs: Are patients with lung cancer a neglected population? Psycho-Oncology, 15(6), 509-516.

Maliski, S., Sarna, L., Evangelista, L., \& Padilla, G. (2003). The aftermath of lung cancer: Balancing the good and bad. Cancer Nursing, 26(3), 237-244.

Mitchell, S.A., Beck, S.L., Hood, L.E., Moore, K., \& Tanner, E.R. (2007). Putting evidence into practice: Evidence-based interventions for fatigue during and following cancer and its treatment. Clinical Journal of Oncology Nursing, 11(1), 99-113.

Montazeri, A., Milroy, R., Hole, D., McEwen, J., \& Gillis, C.R. (2003). How do quality of life data contribute to our understanding of cancer patients' experiences? Quality of Life Research, 12(2), 157-166.

Morasso, G., Capelli, M., Viterbori, P., DiLeo, S., Alberisio, A., Costantini, M., et al. (1999). Psychological and symptom distress in terminal cancer patients with met and unmet needs. Journal of Pain and Symptom Management, 17(6), 402-409.

National Cancer Institute of Canada. (2008). Canadian cancer statistics 2008. Toronto, ON: Author.

Sarna, L., Brown, J.K., Cooley, M.E., Williams, R.D., Chernecky, C., Padilla, G., et al., (2005). Quality of life and meaning of illness of women with lung cancer. Oncology Nursing Forum Online, 32(1), E9-19.

Sarna, L., Evangelista, L., Tashkin, D., Padilla, G., Holmes, C., Brecht, M., et al. (2004). Impact of respiratory symptoms and pulmonary function on quality of life of long-term survivors of non-small cell lung cancer. Chest, 125, 439-445.

Sarna, L., Lindsey, A.M., Dean, H., Brecht, M.L., \& McCorkle, R. (1994). Weight change and lung cancer: Relationships with symptom distress, functional status and smoking. Research in Nursing \& Health, 17(5), 371-379.

Solano, J., \& Higginson, I. (2006). A comparison of symptom prevalence in far advanced cancer, AIDS, heart disease, chronic obstructive pulmonary disease and renal disease. Journal of Pain and Symptom Management, 31(1), 58-68.

Trippoli, S., Varani, M., Lucioni, C., \& Messori, A. (2001). Quality of life and utility in patients with non-small cell lung cancer. Pharmacoeconomics, 19, 855-863.

Voogt, E., van der Heide, A., van Leeuwen, A.F., Visser, A.P., Cleiren, M.P., Passchier, J., et al. (2005). Positive and negative affect after diagnosis of advanced cancer. Psycho-Oncology, 14(4), 262-273.

Whelan, T.J., Mohide, E.S., Willan, A.R., Arnold, A., Tew, A., Sellick, S., et al. (1997). The supportive care needs of newly diagnosed cancer patients attending a regional cancer centre. Cancer, 80, $1518-1524$.

Zabora, J., Brintzenhofeszoc, K., Curbow, B., Hooker, C., \& Piantadosi, S. (2001). The prevalence of psychological distress by cancer site. Psycho-Oncology, 10(1), 19-28. 